\title{
Complete separation of the tube from the mask during removal of a disposable laryngeal mask airway
}

\author{
[La séparation complète $d u$ tube $d u$ masque pendant le retrait d'un masque \\ laryngé jetable]
}

Fred J. Spielman MD

Purpose: To describe a complication of the disposable laryngeal mask airway (LMA).

Clinical features: A 23-yr-old woman underwent a wide local excision of a chest wall melanoma and sentinel node biopsy under general anesthesia. During use of a single-use LMA-Unique ${ }^{T M}$, the airway tube became completely separated from the distal mask (backplate). No sequelae resulted from failure of the airway apparatus. The LMA was examined by LMA North America, and the company stated "no definitive explanation can be made to explain the cause for separation of the airway from the backplate."

Conclusion: Although the use of the LMA is associated with rare and minimal complications, each airway should be carefully inspected before its use for loss of integrity resulting from sterilization or for defects in manufacturing.

Objectif : Décrire une complication survenue avec le masque laryngé jetable (ML).

Éléments cliniques : Une femme de 23 ans devait subir l'excision locale d'un large mélanome de la paroi thoracique et une biopsie du ganglion de Troisier sous anesthésie générale. Pendant l'utilisation du ML-Unique ${ }^{\mathrm{TM}}$ jetable, le tube d'intubation s'est complètement séparée de la partie distale du masque. La défaillance de l'appareil d'intubation n'a pas entraîné de séquelles. Le ML a été examiné par LMA North America et la compagnie a déclaré "qu'aucune interprétation définitive ne pouvait expliquer la cause de la séparation du tube d'avec la partie orale."

Conclusion : L'usage du ML n'a été associé qu'à de rares complications de peu d'importance, mais chaque tube devrait faire l'objet d'un examen méticuleux avant l'usage pour vérifier la présence de défectuosités de fabrication ou résultant de la stérilisation.

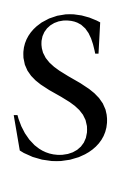

INCE Brain's ${ }^{1}$ publication about the laryngeal mask airway (LMA; LMA ${ }^{\mathrm{TM}}$ North America, San Diego, CA, USA) in 1983, the device has made a significant contribution to airway control. The LMA is popular because it is easy to position, provides a secure airway for spontaneously breathing patients, and affords effective assisted ventilation in elective and emergency situations without requiring endotracheal intubation or visualization of the glottis. Complications associated with the LMA have been reported to occur at insertion, during anesthesia, and upon emergence; however, the difficulties are rare and usually minor. This report describes the occurrence of difficulties with an unused LMAUnique $^{\mathrm{TM}}$ (non-reusable) where the airway tube completely separated from the distal mask (Figure).

\section{Case report}

A 23-yr-old woman weighing $58 \mathrm{~kg}$ underwent a wide local excision of a chest wall melanoma and sentinel node biopsy under general anesthesia. After iv administration of midazolam $2 \mathrm{mg}$, fentanyl $50 \mu \mathrm{g}$, lidocaine $60 \mathrm{mg}$, and propofol $150 \mathrm{mg}$, a size 3 disposable LMA was inserted without difficulty. A soft bite block was used. General anesthesia was maintained with sevoflurane, air, and oxygen, while the patient breathed spontaneously. An attempt was made to remove the LMA at the conclusion of the 93-min operation, when the patient followed commands. No biting was noted on the airway device. A moderate degree of traction was applied to the airway device. The proximal tube of the LMA slid out of the mouth, leaving the distal mask

From the Department of Anesthesiology, University of North Carolina Chapel Hill, North Carolina, USA. Address correspondence to: Dr. Fred J. Spielman, UNC Department of Anesthesiology, Campus Box 7010, 223 Burnett-Womack Bldg,

Chapel Hill, North Carolina 27599-7010, USA. Phone: 919-966-5136; Fax: 919-966-4873; E-mail: fspielman@aims.unc.edu Accepted for publication May 17, 2002.

Revision accepted August 9, 2002. 


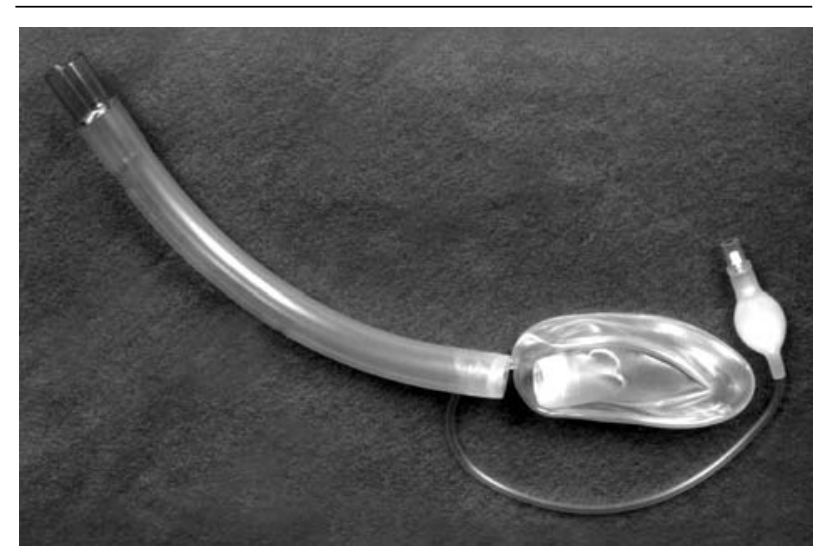

FIGURE The airway tube completely separated from the mask (backplate).

inside the pharynx still attached to the pilot balloon. The remaining portion of the LMA was easily removed by grasping the pilot balloon tubing. At no time during the extubation did the patient's oxygen saturation decrease below 98\%. The patient was discharged home two hours later without apparent complications. Assessment of the LMA showed that the distal mask portion had obviously separated from the proximal tube where they were joined (Figure).

\section{Discussion}

Complications are infrequent during use of the LMA in the operating room. The most common problems encountered include inability to position the LMA correctly, coughing and gagging during placement and removal, laryngospasm, and postoperative sore throat. Mechanical problems are rare. Brimacombe's ${ }^{2}$ analysis of 1500 LMA uses revealed that on two occasions $(0.13 \%)$ the LMA cuff slowly deflated during the operation secondary to a small leak. Verghese and Brimacombe $^{3}$ found that only 44 critical incidents were documented as related to the use of a LMA in 11,910 anesthetics $(0.37 \%)$, and only $18(0.15 \%)$ of these were related to the airway. None of the incidents concerned structural issues associated with the LMA.

Several case reports described the separation, ${ }^{4}$ transection, ${ }^{5,6}$ and shattering of $\mathrm{LMAs}^{7}$ these reports all involved reusable LMAs. Repeated sterilization with heat and chemicals were thought to have caused degradation of the silicone, resulting in brittleness, cracking, and in one case, ${ }^{7}$ "...the friability of cheddar cheese." On no occasion was it known how many times a LMA had been used.
LMA $^{\mathrm{TM}}$ North America suggests that the LMAClassic $^{\mathrm{TM}}$ mask can be reused up to 40 times. Each instance that a reusable airway is considered for use it must be tested for elasticity, and the airway should be discarded if the tube kinks when flexed to $180^{\circ} .^{8}$ The integrity of the cuff ought to be verified by inflating with a volume of air $50 \%$ greater than the recommended maximum. There should be a system in place to verify the number of times the LMA has been sterilized.

The LMA was sent to LMA $^{\mathrm{TM}}$ North America for further inspection and analyses. Upon examination of the LMA-Unique ${ }^{\mathrm{TM}}$ referenced in this case report, LMA $^{\mathrm{TM}}$ North America noted, "the airway has become completely separated from the backplate. There is evidence of the solvent bond on the area of the airway, which would have inserted into the backplate. The outer diameter of the airway and the inner diameter of the backplate are within specifications and appear to be a good fit when put together. After examination of this LMA-Unique ${ }^{\mathrm{TM}}$ and manufacturing records, no definitive explanation can be made to explain the cause for separation of the airway from the backplate."

Biting on the LMA during the process of device removal might be an important factor in the separation, ${ }^{4}$ transection, ${ }^{5}$ and shattering ${ }^{7}$ of airways. As is recommended, the LMA should be removed with the cuff inflated either after full recovery of airway reflexes or while the patient is deeply anesthetized, with a bite block in place. An advantage to removing the LMA before emergence is that this would diminish the chance of the patient biting and damaging the airway. Two studies ${ }^{9,10}$ have demonstrated a high incidence of clenched teeth and biting the LMA, 26\% and $10 \%$, respectively, when the airway is removed after laryngeal reflexes have returned.

In summary, although the use of the LMA is associated with rare and minimal complications, each airway should be carefully inspected before its use for loss of integrity resulting from sterilization or for defects in manufacturing.

\section{References}

1 Brain AIJ. The laryngeal masks-a new concept in airway management. Br J Anaesth 1983; 55: 801-5.

2 Brimacombe J. Analysis of 1500 laryngeal mask uses by one anaesthetist in adults undergoing routine anaesthesia. Anaesthesia 1996; 51: 76-80.

3 Verghese C, Brimacombe JR. Survey of laryngeal mask airway usage in 11,910 patients: safety and efficacy for conventional and nonconventional usage. Anesth Analg 1996; 82: 129-33.

4 Khoo ST. The laryngeal mask airway—an unusual com- 
plication (Letter). Anaesth Intensive Care 1993; 21 :

249-50.

5 Kramer-Kilper OT. Removal of laryngeal mask airway during light anaesthesia (Letter). Anaesthesia 1992; 47: 816.

6 Crawford $M$, Davidson $G$. A problem with a laryngeal mask airway (Letter). Anaesthesia 1992; 47: 76.

7 Squires SJ. Fragmented laryngeal mask airway (Letter). Anaesthesia 1992; 47: 274.

8 Asai T, Vaughan RS. Misuse of the laryngeal mask airway (Editorial). Anaesthesia 1994; 49: 467-9.

9 Gataure PS, Latto IP, Rust S. Complications associated with removal of the laryngeal mask airway: a comparison of removal in deeply anaesthetised versus awake patients. Can J Anaesth 1995; 42: 1113-6.

10 Reddy SVG, Win N. Brain laryngeal mask - study in 50 spontaneously breathing patients. Singapore Med J 1990; 31: 338-40. 